\title{
Pulmonary Artery Hypertension in SLE
}

\author{
B. K. S. Sastry ${ }^{1}$ \\ ${ }^{1}$ Department of Cardiology, CARE Hospitals, Hyderabad, Telangana, \\ India62106107
}

Ind J Car Dis Wom 2021;6:106-107.

Pulmonary hypertension $(\mathrm{PH})$ is characterized by pulmonary artery mean pressure more than $20 \mathrm{~mm} \mathrm{Hg}$. It is caused by diverse diseases. It is classified into five categories, based on etiology, pathophysiology, natural history, and response to treatment. Group $1 \mathrm{PH}$, also called pulmonary artery hypertension (PAH), includes many different diseases including $\mathrm{PH}$ due to connective tissue disease (CTD). The most common CTD to cause PAH is systemic sclerosis. PAH is also commonly seen in mixed connective tissue disease (MCTD), systemic lupus erythematosus (SLE), and rheumatoid arthritis. There is no uniform pathophysiologic mechanism for PH. Molecular pathogenesis of PAH is not completely known, and thus the therapeutic targets in the management of PAH are limited. This makes the prognosis and treatment of PAH due to CTD more difficult.

In this context, the paper published by Baisya et al, which provides insights into the molecular mechanism of PAH in SLE, is a step in the right direction, and I congratulate them for that. Baisya et al conducted a cluster analysis of auto antibodies in 71 patients with SLE-associated PAH. They concluded that the cluster with no definite antibody association had the highest mean right ventricular systolic pressure (RVSP) or severe PAH. ${ }^{1}$

One of the limitations of their study, as rightly acknowledged by the authors, is that the diagnosis of PAH is based on echocardiography alone while the gold standard is right heart catheterization. It is quite understandable that patients' acceptance of cardiac catheterization would be quite low in the Indian context. Instead of diagnosing PH solely on the basis of tricuspid regurgitation (TR) jet velocity, they could have made the diagnosis of $\mathrm{PH}$, based on the guidelines provided by the American Society of Echocardiography. ${ }^{2}$ However, it is likely that the diagnosis of PAH is valid in this cohort of patients, considering the criteria they used.

Cluster analysis is useful in identifying the risk factors and mechanisms of the disease and developing therapeutic targets. Reported incidence of PAH in SLE and autoantibody
Address for correspondence B K S Sastry, MD, DM. FACC, Department of Cardiology, CARE Hospitals, Nampally, Hyderabad, Telangana, 500001, India (e-mail: bkssastry@hotmail.com).

associations with SLE PAH are somewhat divergent and appear to be based on geographic location and ethnicity. ${ }^{3,4}$ Incidence of PAH in SLE is relatively less in Taiwanese and Caucasians, while it is more in Pakistanis and African Americans. ${ }^{5-7}$ There are significant interethnic differences observed in the REVEAL registry done in the US. ${ }^{8}$ Similarly, different antibodies are associated with SLE PAH, as reported in different studies. In a UK study, association with lupus anticoagulant was reported, while the French reported association with anti-Ro and anti-La antibodies and the Chinese reported association with anti-RNP and anticardiolipin antibodies. ${ }^{9-12}$ This kind of data strongly suggests the possible role played by the underlying genetic factors, and this study has to be seen as part of a bigger picture. Often there is overlap between different autoimmune rheumatological diseases, their phenotypes and prevalent antibodies. ${ }^{13}$ Keeping in mind wide variations and smaller size of each cohort, one may consider a pooled analysis of PAH associated with different autoimmune diseases.

Antibodies interact closely with cytokines in pathogenesis of diseases. In an interesting study, researchers from the Stanford University and University of Sheffield carried out cluster analysis of circulating cytokines and chemokines in patients with PAH..$^{14}$ They identified four clusters and established an association with prognosis, although there were no difference in phenotypes. Larger studies that include patients with PAH associated with different CTD, and analyze antibody clusters as well as cytokine profiles, may throw more light on pathogenesis and prognosis and help identify therapeutic targets. A truly personalized precision medicine may not be far off.

\section{Source of Funding \\ None}

\section{Conflict of Interests}

None.
DOI https://doi.org/ 10.1055/s-0041-1732503 (c) 2021. Women in Cardiology and Related Sciences.

This is an open access article published by Thieme under the terms of the Creative Commons Attribution-NonDerivative-NonCommercial-License, permitting copying and reproduction so long as the original work is given appropriate credit. Contents may not be used for commercial purposes, or adapted, remixed, transformed or built upon. (https://creativecommons.org/licenses/by-nc-nd/4.0/).

Thieme Medical and Scientific Publishers Pvt. Ltd. A-12, 2nd Floor, Sector 2, Noida-201301 UP, India 


\section{References}

1 Baisya R, Devarasetti PK, GSR Murthy, Rajasekhar L . Autoantibody clustering in systemic lupus erythematosus associated pulmonary arterial hypertension. Ind J Car Dis Wom 2021. doi: $10.1055 / \mathrm{s}-0041-1732510$

2 Rudski LG, Lai WW, Afilalo J, et al. Guidelines for the echocardiographic assessment of the right heart in adults: a report from the American Society of Echocardiography endorsed by the European Association of Echocardiography, a registered branch of the European Society of Cardiology, and the Canadian Society of Echocardiography. J Am Soc Echocardiogr 2010;23(7):685-713, quiz 786-788

3 Huang C, Li M, Liu Y, et al. Baseline characteristics and risk factors of pulmonary arterial hypertension in systemic lupus erythematosus patients. Medicine (Baltimore 2016;95(10):e2761

4 Lai Y-C, Potoka KC, Champion HC, Mora AL, Gladwin MT. Pulmonary arterial hypertension: the clinical syndrome. Circ Res 2014;115(1):115-130

5 Chen H-A, Hsu T-C, Yang S-C, et al. Incidence and survival impact of pulmonary arterial hypertension among patients with systemic lupus erythematosus: a nationwide cohort study. Arthritis Res Ther 2019;21(1):82

6 Asif S, Rasheed A, Mahmud T-E-H, Asghar A. Frequency and predictors of pulmonary hypertension in patients with Systemic Lupus Erythematosus. Pak J Med Sci 2019;35(1):86-89

7 Mizus M, Li J, Goldman D, Petri MA. Autoantibody clustering of lupus-associated pulmonary hypertension. Lupus Sci Med 2019;6(1):e000356
8 Chung L, Liu J, Parsons L, et al. Characterization of connective tissue disease-associated pulmonary arterial hypertension from REVEAL: identifying systemic sclerosis as a unique phenotype. Chest 2010;138(6):1383-1394

9 Prabu A, Patel K, Yee C-S, et al. Prevalence and risk factors for pulmonary arterial hypertension in patients with lupus. Rheumatology (Oxford 2009;48(12):1506-1511

10 Li M, Wang Q, Zhao J, et al. CSTAR co-authors. Chinese SLE Treatment and Research group (CSTAR) registry: II. Prevalence and risk factors of pulmonary arterial hypertension in Chinese patients with systemic lupus erythematosus. Lupus 2014;23(10):1085-1091

11 Lian F, Chen D, Wang Y, et al. Clinical features and independent predictors of pulmonary arterial hypertension in systemic lupus erythematosus. Rheumatol Int 2012;32(6):1727-1731

12 Hachulla E, Jais X, Cinquetti G, et al. French Collaborators Recruiting Members(*). Pulmonary arterial hypertension associated with systemic lupus erythematosus: results from the French pulmonary hypertension registry. Chest 2018;153(1):143-151

13 Molano-González N, Rojas M, Monsalve DM, et al. Cluster analysis of autoimmune rheumatic diseases based on autoantibodies. New insights for polyautoimmunity. J Autoimmun 2019;98:24-32

14 Sweatt AJ, Hedlin HK, Balasubramanian V, et al. Discovery of distinct immune phenotypes using machine learning in pulmonary arterial hypertension. Circ Res 2019;124(6): 904-919 